\title{
Gaudentes in Domino
}

Tereza Virginia Ribeiro Barbosa Universidade Federal de Minas Gerais

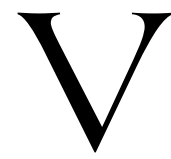

amos comentar, neste ensaio, um filme de Pier Paolo Pasolini, Uccellacci e Uccellini (Gaviōes e Passarinhos, Itália, 1966). ${ }^{1}$ Esse grande produto não poderá ser aqui extensivamente estudado, conquanto cada elemento - texto, trilha sonora, imagem, locaçóes, fontes e aspectos intertextuais (com a Bíblia, obras literárias, símbolos, a filmografia pasoliniana, etc) - merecesse longa investigação. Não se trata de uma análise fílmica rigorosa; o texto traz uma reflexão sobre um pequeno aspecto da película que julgamos ter permanecido, até agora, sem a devida apreciação dos críticos. É nossa intenção focalizar uma figura, ou, pensando melhor, um posicionamento determinado, que parte dos personagens incorpora e transmite: a alegria.

Uccellacci e Uccellini apresenta o Santo de Assis de forma rápida, mas incisiva. Poderíamos afirmar inclusive que São Francisco é, na película, um coadjuvante. Todavia, embora sua presença seja pequeníssima, o que de resto é muito adequado para o fundador da ordem dos frades menores, sua intervenção proporciona cenas de vigor e beleza indiscutíveis.

Temo-lo na tela por três vezes. Ele prega para as aves; envia dois frades, Cicillo e Ninetto para pregarem aos gaviōes e aos passarinhos; faz uma admoestação final. As últimas palavras de São Francisco no filme são, na verdade, palavras do papa Paulo VI. ${ }^{2}$ O pontífice, em seu discurso aos

${ }^{1}$ Agradecemos a Patrícia Peterle a oferta do DVD Uccellati e Uccellini; a ela todas as alegrias do céu.

${ }^{2}$ As palavras de Paulo VI estão em seu discurso aos padres conciliares da congregação geral 142 sobre sua visita à ONU. Cf. <http://www.vatican.va/ holy_father/paul_vi/speeches/1965/documents/hf_p-vi_spe_19651005_ resoconto-viaggio_po.html>. Conferir também: VIANO, 1993, p. 151. 
padres conciliares, profere um parágrafo que se inicia do seguinte modo: "De justiça tem o mundo grande necessidade, e de justiça quer Cristo que sintamos fome e sede..." E continua; porém, o trecho seguinte de sua fala será utilizado por Francisco, tomando-lhe as palavras, ecoando-o no filme:

E nós sabemos que a justiça é progressiva, e que, à medida que a sociedade progride, torna-se mais profundamente consciente da sua imperfeita composição, vindo então à luz os gritos e os clamores suscitados pelas desigualdades que continuam a atormentar a humanidade.

Como se vê, o cineasta harmoniza política e religião ou, mais especificamente, cristianismo e marxismo visto que essas palavras se inserem na narrativa de uma personagem do filme declaradamente comunista, um corvo que relata a história do santo franciscano. Aliás, este último é o foco de grande parte das análises da obra, o que no nosso ponto de vista é uma leitura datada e limitada. Nossa leitura é consoante, entre outros, com Barroso. ${ }^{3}$ E justificamos nossa posição.

De forma crua, sem sofisticaçôes, Pasolini, por meio do que ele próprio chama de "transposição alegórica", 4 deixará falar o corvo (a personagem comunista a que nos referimos no parágrafo anterior), pássaro falante que irá levar os dois protagonistas (os mesmos atores que fazem os frades pregadores na história narrada), por uma estrada em construção e que não se sabe aonde vai terminar. $\mathrm{O}$ corvo declara-se um intelectual marxista, filho do Vacilo e da Consciência. Reside na "Rua Karl Marx número setenta vezes sete". O endereço é curioso, pois reúne o nome do fundador da ideologia apregoada e uma expressão claramente bíblica: "setenta vezes sete". O partido político é claro, sem subterfúgios, a religiosidade, contudo está obscurecida. E embora esteja para este mesmo corvo destinada a morte, ele ocupará o privilegiado lugar de um protagonista. Mas a ave comunista, ao contrário do correlato de Poe, durante todo o filme, oferece muitas respostas.

\footnotetext{
${ }^{3}$ AMOROSO, 2002, p. 12-13.

${ }^{4}$ MAGGI, 2009, p. 114.
} 
Digamos que, em termos do teatro grego, o corvo seria o protagonista, o pai Totó, deuteragonista, e o rapazola Ninetto, o tritagonista.

Assim, temos um corvo falante, que assume a doutrinação dos caminheiros e que acaba por representar toda a crise ideológica que enfrenta a Itália nos dois anos após a morte de seu líder comunista, Palmiro Togliatti, falecido em 21 de agosto de 1964. O filme exibe, inclusive, cenas de seu funeral incorporando-as à narrativa. ${ }^{5}$ A obra, como um todo, reflete o instante da escolha entre capitalismo e marxismo. Seu final apocalíptico, porém, prevê uma situação nada confortável para os seguidores de Karl Marx. O filme tem um final violento depois de uma narrativa trágica; os grandes símbolos do marxismo na história têm tons sombrios, pesados e negativos. Um será eliminado, mais exatamente, devorado, o outro, enterrado. Acrescente-se que durante o funeral são registradas imagens que mostram um marxismo desafinado: as pessoas que vão ao funeral rezam e persignam-se diante do defunto.

Além disso, observemos o incômodo momento - que Viano nomeia "cena chinesa" ${ }^{6}$ - da casa operária visitada pelos andarilhos. Deparamos com uma insólita situação. Uma mulher desce de uma alta escada com um ninho na mão. Em pleno dia, ela grita para o filho que choraminga faminto: "dorme que ainda é noite". Ao ser interpelada pelos credores, ela se ajoelha e se arrasta no chão suplicante, embora apresente feições inexpressivas. Ao fundo, um operário impassível espera pela refeição que ela prepara. Os visitantes se vão, ela serve a comida e o homem, visivelmente entristecido, toma lugar à mesa e se prepara para comer uma sopa de ninho. Ele se alimenta olhando direta e desafiadoramente para a câmera. O episódio é desconfortável. A pobreza que mostra a cena não combina com o alimento servido, uma iguaria na China. De acesso restrito pelo preço elevado, pelas dificuldades de obtenção, pelo apuro na limpeza e preparo, a Sopa de Ninho representa não somente a tradição milenar chinesa, mas requinte e refinamento para poucos. ${ }^{7}$

\footnotetext{
5 VIANO, 1993, p. 147.

${ }^{6}$ VIANO, 1993, p. 152.

7 TAN, 2007, p. 28.
} 
O inusitado da composição relatada nos faz ver o trecho marcado pela ironia. Como conciliar interpretaçôes tão opostas? Ademais a China pretendia-se uma das pioneiras em promover a sociedade igualitária baseada na propriedade comum e no controle dos meios de produção. Se a Europa enxerga a indigência na "cena chinesa", a China veria, por seu lado, o luxo e a sofisticação. Todavia, Pasolini não parece estar possuído de entusiasmo acrítico: o descompasso presente no trecho e, por extensão, em todo o filme, apesar da onipresença da música que remete às repúblicas soviéticas, nos mostra outras faces do país, como os trabalhadores em extrema privação.

Veremos que não há otimismo em relação ao regime de Mao. Pensamos que estes elementos constroem uma crítica profunda e, ainda, debochada. Maurizio Viano ${ }^{8}$ indica a utilização recorrente na película de uma resposta de Mao Tse-Tung, líder revolucionário e dirigente da República Popular da China por vinte e sete anos. O grande comunista teria se notabilizado por uma resposta reproduzida com frequência e em circunstâncias difíceis: "Bah!". É essa mesma atitude que o filme apresenta em diversos momentos (a ponto de o termo "homenagem" não poder denominar todos os casos), com personagens distintas.

Deste modo a leitura marxista de Uccellacci e Uccellini nos parece demasiado tendenciosa e marcada por um estigma que hoje não mais procede. Ocorre ainda que o cristianismo primitivo carrega valores marxistas, sem dúvida. Ou melhor, reformulemos a conclusão apressada: mais acertado seria afirmar que o marxismo assimila valores cristãos caros a Pasolini: justiça, igualdade, partilha de bens, afeto.

Neste sentido, incorporada a "esperança" cristã, a composição da película é, paradoxalmente, trágica, grave e bem humorada. Os opostos se reúnem em uma figura emblemática, o poverello de Assis que se dedicou ao cuidado dos pobres e dos leprosos, que se despojou de seus bens e que cantou, feliz, até a hora de sua morte (é o que narra Juliano de Spira, frade alemão que possivelmente teria escrito uma das vidas de São Francisco).

${ }^{8}$ VIANO, 1993, p. 149. 
(...) Quando sentiu que a hora da morte se aproximava, chamou a si dois frades, aos quais ordenou que alegremente cantassem ao Senhor os louvores pela sua morte iminente. Ele, porém, da forma que pôde, entoou este salmo: Com minha voz clamei ao Senhor, com minha voz supliquei ao Senhor (Sl 141, 2-8). Um dos frades presentes, mais solícito que os outros, disse-lhe: "Bom pai, teus filhos vão ficar sem pai! Lembra-te dos que deixas na orfandade e, perdoadas todas as culpas, digna-te consolar tanto os presentes quanto os futuros com tua santa bênção". O tão piedoso pai respondeu: "Meu filho, já estou sendo chamado pelo Senhor! Perdôo todas as ofensas e culpas dos meus irmãos, presentes ou ausentes; e absolvo-os como posso. E tu, meu filho, notificando isso aos outros, de minha parte, abençoa-os todos". Depois, pediu que se lesse o Evangelho segundo João no ponto que começa: Antes do dia da festa da Páscoa (Jo 13,11); quis também que lhe colocassem o cilício e o aspergissem com cinza. E assim, cercado pelos filhos que choravam, o santo pai adormeceu felizmente no Senhor (At 7,60). ${ }^{9}$

${ }^{9}$ Todas as citaçōes franciscanas foram retiradas do site da Província dos Capuchinhos de São Paulo, http://www.procasp.org.br/fontes.php As traduções do latim ou do italiano antigo usado por Francisco são de autoria de Frei José Carlos Corrêa Pedroso. Os grifos são todos nossos. DE SPIRA, Juliano. Vida de Francisco, 69: “(...) donec tandem mortis horam instare cognoscens, duos ad se fratres vocavit, quibus de transitu eius vicino Laudes alacriter Domino decantare praecepit. Ipse vero, prout potuit, in hunc psalmum prorupit: "Voce mea ad Dominum clamavi, voce mea ad Dominum deprecatus sum (cfr. Ps 141,2-8)". Unus autem e fratribus qui adstabant, pro cunctis sollicitus, dixit ad eum: "Heu, pater benigne, ecce filii tui remanent sine patre! Recordare igitur orphanorum quos deseris, et, omnibus culpis remissis, tam praesentes quem absentes tua sancta benedictione consolari digneris". Cui piissimus pater respondit: "Ecce ego quidem iam vocor a Domino, fili! Fratribus vero meis tam absentibus quam praesentibus omnes offensas et culpas remitto, et eos sicut possum absolvo; quibus tu haec, fili, denuntians, ex parte mea omnibus benedicas". Porro Evangelium secundum Iohannem ab eo loco ubi incipit: Ante diem festum paschae (Ioa 13,1) sibi legi poposcit; deinde se cilicio superponi cinereque conspergi praecepit. Et sic, filiis circumstantibus et lugentibus, pater sanctus in Domino feliciter obdormivit (cf. Act 7,60). 
$\mathrm{Na}$ Legenda dos três companheiros, a primeira biografia do santo, o autor seguirá o mesmo caminho e mencionará sempre a morte de Francisco como um acontecimento feliz. São frases suas:

Depois de vinte anos desde que aderira perfeitissimamente a Cristo, seguindo a vida e os vestígios dos apóstolos, Francisco, o varão apostólico, no ano 1226 da Encarnação do Senhor, no dia quatro de outubro, um domingo, migrou com a maior felicidade para Cristo, conseguindo a vida eterna depois de muitos trabalhos, apresentando-se dignamente diante do seu Senhor ${ }^{10}$

e, ainda,

(...) mas depois de seu felicíssimo trânsito, todos os irmãos presentes e muitíssimos leigos viram perfeitamente seu corpo ornado com os estigmas de Cristo. ${ }^{11}$

Assim, acrescido o imaginário popular, São Francisco é conhecido como o santo da alegria. Não somente aquela felicidade etérea e idealizada dos beatos (essa também) que sofrem martírios e que guardam sua felicidade contidamente no coração. Mas aquela palpável, pois Francisco externaliza claramente seu regozijo. "Achou que viver para o mundo era um opróbrio, amou os seus até o fim e recebeu a morte cantando." ${ }^{2}$ Ele restaura e trata os sofridos e por isso, onde passava, enchia a todos de júbilo.

${ }^{10}$ LEGENDA DOS TRÊS COMPANHEIROS, 68: 1 Post viginti autem annos ex quo perfectissime Christo adhaesit, apostolorum vitam et vestigia sequens (cfr. 1Pet 2,21), apostolicus vir Franciscus, anno dominicae Incarnationis millesimo ducentesimo vigesimo sexto, quarto nonas octobris, die dominico, felicissime migravit ad Christum post multos labores requiem aeternam adeptus et digne Domini sui conspectibus praesentatus.

${ }^{11}$ LEGENDA DOS TRÊS COMPANHEIROS, 70: 1 Sed post felicissimum eius transitum omnes fratres qui aderant et saeculares quamplurimi manifestissime viderunt corpus suum Christi stigmatibus decoratum.

${ }^{12}$ DE CELANO, Tomás. Vida de Francisco (2), 214: Nam mundo vivere (cfr. Gal 2,20) duxit opprobrium, dilexit suos in finem (cfr. Ioa 13,1), mortem cantando suscepit. 
Houve, então, um grande ajuntamento do povo (At 21,30) da cidade de Assis, louvando a Deus (Lc 2,13) em unânime alegria, porque confiava a eles tão grande tesouro. De início, era grande o pranto dos filhos pela perda de tão grande pai; mas, logo depois, mudouse em canto de alegria. Pois viam a novidade criada pelo Senhor sobre a terra $(\mathrm{Jr} 31,22)$. Viam um milagre digno de alegria e não de choro: o sagrado corpo ornado com as chagas de Cristo. Viam seus membros, antes doentes e rígidos, agora facilmente flexíveis, conforme a vontade de quem os tocasse. E também a carne, antes dura e lívida, reassumiu a delicadeza de uma criança, mostrando um admirável candor, como se, com sua grande beleza, apresentasse uma imagem do corpo glorificado. Era uma glória ver na carne tão branca os sinais da abertura dos cravos (Jo 20,25): cravos negros como o ferro, formados de carne, no meio dos pés e das mãos, e o lado direito marcado pelo sagrado sangue. Os filhos choravam pela alegria do coração $(\operatorname{Lm} 5,15)$ e beijavam no pai os sinais do sumo Rei. ${ }^{13}$

Em outro manuscrito veremos Francisco exuberante:

${ }^{13}$ DE SPIRA, Juliano. Vida de Francisco, 71: Factus est itaque concursus populorum (cfr. Act 21,30) civitatis Assisii Deum unanimi iucunditate laudantium (cfr. Luc 2,13), eo quod tantum illis dignaretur commendare depositum. Erat autem primitus pro tanti patris subtractione planctus filiorum non modicus, qui non multo post in laetitiae canticum est conversus. Videbant namque novam illud, quod fecerat Dominus super terram (cfr. Ier 31,22); videbant, inquam, non planctu sed plausu dignum miraculum, sacrum videlicet corpus, Christi stigmatibus decoratum. Aspiciebant membra eius, morbida prius et rigida, iam tractabiliter pro tangentis se voluntate flectentia; carnem quoque, duram prius et lividam, veluti pueruli teneritudine iam resumpta, mirando candore nitentem, et quasi carnis glorificatae speciem prae decoris magnitudine praetendentem. Gloriosum tunc erat in carne tam candida videre similitudinem fixurae clavorum (cfr. Ioa 20,25) immo, nigros ut ferrum cravos ex ipsa carne formatos in medio pedum et manuum, dextrumque latus sacro sanguine rubricatum. Lacrimabantur itaque filii prae gaudio cordis (cfr. Lam 5,15), et osculabantur in patre signacula summi Regis. 
O santo ficava exultante com essas coisas, quando sabia que seus filhos eram capazes por si mesmos de dar exemplos de santidade, cobrindo com suas bênçãos os frades que, mais dignos do que se possa dizer, por palavras ou ações, levavam os pecadores para o amor de Cristo. ${ }^{14}$

Destacamos nos trechos as informações atinentes à alegria: "unânime alegria"; [o pranto] "mudou-se em canto de alegria"; "[v]iam um milagre digno de alegria"; "uma imagem do corpo glorificado" e, finalmente "alegria do coração". Segue-se em outra passagem a informação de que o santo exultava diante da santidade dos outros. Por tudo isso, tomamos liberdade de tantas citações e entendemos ter comprovado ser Francisco o santo da alegria e os franciscanos os "gaudentes in Domino".

No percurso, resgatamos, portanto, a leitura da alegria na película e atribuímos a ela o tom leve, agradável e venturoso do drama - que na perspectiva do corvo, é na verdade, uma tragédia - de Uccellacci e uccellini, um filme que narra as vicissitudes e tribulações do mundo moderno, mas que guarda singeleza e contentamento.

E pedimos vênia para citar uma última passagem de Tomás de Celano. Trata-se de quando Francisco, atormentado mais que de costume em sua grave doença, recebe de Cristo a promessa que descreve ao seu companheiro frade Tomás:

"Se toda a mole da terra e o universo inteiro fossem de ouro sem preço e soubesses que, livre de toda dor, haverias de receber como prêmio por teus duros sofrimentos um tesouro tão glorioso que, comparado com ele, todo aquele ouro seria um nada e nem mereceria ser mencionado, não te sentirias feliz de suportá-los de boa vontade por mais alguns momentos?"

\footnotetext{
${ }^{14}$ DE CELANO, Tomás. Vida de Francisco, 155: Exsultabat sanctus in talibus, cum suos filios audiebat ex se ipsis exempla sanctitatis educere, benedictionibus omni acceptione dignissimis (cfr. 1Tim 1,15) fratres illos accumulans, qui verbo vel opere (cfr. Col 3,17) ad Christi amorem inducerent peccatores.
} 
O santo respondeu: "É claro que me alegraria, alegrar-me-ia acima da medida". "Podes exultar, então", disse-lhe o Senhor, "porque tua doença é uma garantia de meu reino e, pelos merecimentos da paciência, podes ter a segurança e a certeza que terás a herança desse reino!" Que alegria imensa terá sentido o homem feliz que recebeu essa promessa! ${ }^{15}$

Reiteramos então que a presença do frade de Assis em Uccellacci e Uccellini pulsa desde a abertura na apresentação dos créditos iniciais projetados sobre uma imagem congelada da lua semiencoberta por nuvens: os nomes de todos os membros da equipe, além de escritos como de praxe, são cantados como num moteto. ${ }^{16}$

Mas antes que o filme fosse iniciado, em processo de criação, a alegria de Francisco já paira na cena. Pasolini comenta, em carta, ${ }^{17}$ que teria escolhido para este filme dois atores cômicos, Totó, um picaresco incomparável, e Ninetto Davoli. ${ }^{18}$ Após esta boa disposição de espírito na escolha dos atores e na abertura da película, vemos pai e filho caminhando em uma estrada deserta e em construção. Totó declara: "com a lua não se brinca”. A oposição está materializada: canção divertida e advertência. Percebe-se que tudo se concatena em fios opostos que se cruzam.

${ }^{15}$ DE CELANO, Tomás. Vida de Francisco, 213: Si tota terrae moles (cfr. Is 40,12 ) et machina mundi aurum esset sine pretio (cfr. Ps 43,13) pretiosum, et tibi pro iis quae pateris duris molestiis, omni dolore sublato, daretur in praemium thesaurus gloriae tantae, cui praedicti auri comparatio (cfr. Sap $7,9)$ nulla esset, vel etiam nominari non digna, nonne gauderes, libenter sustinens quae sustines ad momentum?". 5 "Gauderem utique", ait sanctus, "et supra modum (cfr. 2Cor 4,17) gauderem". 6 "Exsulta igitur", dixit illi Dominus, "quia regni mei est arrha infirmitas tua, et per patientiae meritum securus et certus (cfr. Sap 7,23) eiusdem regni haereditatem (cfr. Eph 5,5) exspecta!". 7 Sed quanta putas exsultatione gavisum hominem tam felici promissione beatum?

16 VIANO, 1993, p. 154. Moteto é um gênero musical que teve seu apogeu no século XIII. A forma como o elenco é cantado é inusitada.

${ }^{17}$ MAGGI, 2009, p. 112.

${ }^{18}$ VIANO, 1993, p. 153. 
A lua estabelecerá uma metáfora importante ao longo da narrativa. Ela tem tanto a sua força cósmica natural, quanto aquela pessoal e particular personificada em uma prostituta de nome Luna, da qual pai e filho se servem para satisfazerem seus apetites. Além de integrar o primeiro verso do Cântico das Criaturas, a lua evoca ainda para uma passagem da Legenda dos Três companheiros, 68, em que o autor delineia um quadro bem semelhante ao dos créditos apresentados em moteto na abertura do filme: "Um de seus discípulos, famoso por santidade, viu sua alma subir diretamente ao céu como uma estrela do tamanho da lua, e quase tão brilhante como o sol. Elevava-se sobre muitas águas e tinha por baixo uma nuvenzinha branca."

Lua, energia sexual natural, necessidades básicas (de comer, defecar e descansar) desenham personagens comuns e, até certo ponto, ingênuas. ${ }^{19}$ O corvo define-as como inocentes e simples e associa estas qualidades à religiáo. Maurizio Sanzio Viano ${ }^{20}$ vê nestes opostos (marxismo e cristianismo; ideologia e inocência; corpo com suas necessidades básicas e filosofia marxista; palavra e imagem contemplada) a tessitura de uma trama cuidadosamente sofisticada.

Mas a leveza não cessa aí. Há uma leveza em instruir, educar, ensinar. Nesse viés, propomos, em anuência com Santos, que a história seja interpretada à moda das narrativas de Esopo.

Gaviōes e passarinhos apresenta a mesma estrutura aberta de uma fábula, em que a narração se espraia, descentralizando a ação, mantendo, no entanto, subjacente, a progressão dramática. Dessa forma, o início da narração não significa efetivamente o começo, mas a retomada de uma história já narrada; e o "final feliz" não se configura como conclusão, mas funciona como um gancho propiciador do início de uma nova narrativa - "A viagem mal começou e o caminho já acabou”, informa-nos um dos letreiros do filme. ${ }^{21}$

19 VIANO, 1993, p.156.

${ }^{20}$ VIANO, 1993, p.152.

${ }^{21}$ SANTOS, 2004, p. 1. 
A fábula poderia ser mais ou menos assim: O homem e o corvo. Um homem segue com seu filho em uma estrada que não sabia para onde os levava. No meio do caminho apareceu-lhe um corvo que se pôs a conversar. Disse que se chamava Ideologia, que tinha uma história antiga para contar e pôs-se a falar. O homem e o filho escutaram a história enquanto caminhavam. O corvo falava de um homem santo que havia mandado dois de seus companheiros pregarem a vontade divina para pássaros que, por natureza, eram inimigos um do outro. E isso foi feito. Os pássaros apreenderam a pregação, porém um dia, de súbito, um gavião convertido, não suportando o instinto, praticou seu vôo rasante de sempre e trucidou um passarinho que, desprevenido, comia seu grão. $\mathrm{O}$ homem ouviu atentamente, porém, ao fim da jornada já estava faminto e enfastiado de tanta conversa. Neste instante, em súbita exasperação, o homem mata o corvo e come-o assado.

Moral da história: suportamos a ideologia até a fome chegar. Em termos acadêmicos: o corpo vence a tirania da mente..$^{22} \mathrm{Ou}$ : A fábula demonstra que as palavras não servem quando chega a fome. E, no decurso da película, em consonância com a moral emitida, reafirma-se a existência de um outro tipo de discurso, o gestual mais próximo da realidade. ${ }^{23}$ Essa "moral da história" será assumida quando Cicillo e Ninetto, ao pregarem para os pássaros, compreendem que os gavióes (a ciência, segundo o ornitólogo amador Frei Cicillo) entendem quando os pregadores emitem guinchos; contudo, as andorinhas e pardais (a fé, no dizer do mesmo frade), quando chilream e gorjeiam os oradores, nada compreendem. Estes necessitam de que seus interlocutores componham uma dança em saltinhos, só então tudo fica claro e transparente.

Ideológico e cômico, ${ }^{24}$ Pasolini dedica cerca de trinta minutos de seus oitenta e nove minutos de fita ao franciscanismo. E se Maurizio Viano

\footnotetext{
${ }^{22}$ VIANO, 1993, p. 151.

${ }^{23}$ VIANO, 1993, p. 152.

${ }^{24}$ VIANO, 1993, p. 151.
} 
vê na tríade pai, filho e corvo uma caricatura da Santíssima Trindade, ${ }^{25}$ nós percebemos, antes, uma caricatura do intelectual de esquerda que não consegue propor uma humanidade melhor do que, na Idade Média, propôs o revolucionário de Assis. Antes de ser um Espírito Santo (antes de ser Francisco, no nosso entender) que traz consigo a sabedoria e o discernimento, o intelectual marxista tornou-se um pássaro agourento e perturbador.

Afigura-se-nos que Pasolini, um pouco identificado com o corvo marxista, anseia de alguma forma pela alegria perfeita e duradoura dos simples, dos freis Francisco, Cicilo e Nineto.

(...) um dia o bem-aventurado Francisco chamou Frei leão em Santa Maria dos Anjos e disse: "Frei Leão, escreve". O qual respondeu: "Eis, estou pronto". "Escreve - disse - qual é a verdadeira alegria. Vem um mensageiro e diz que todos os mestres de Paris vieram para a Ordem, escreve: não é a verdadeira alegria. Também que todos os prelados ultramontanos, arcebispos e bispos; também que o rei da França e o rei da Inglaterra: escreve, não é a verdadeira alegria. Também, que os meus frades foram aos infiéis e converteram-nos todos à fé; também que tenho tamanha graça de Deus que curo doentes e faço muitos milagres: eu te digo que em tudo isso não há verdadeira alegria. Mas qual é a verdadeira alegria? Volto de Perusa e de noite profunda venho aqui e é tempo de inverno, barrento e tão frio, que se formam bolinhas de água fria congelada na barra da túnica e me batem sempre nas pernas, e corre o sangue dessas feridas. E todo no barro, no frio e no gelo, chego à porta, e depois que bati e chamei longamente, vem um frade e pergunta: Quem é? Eu respondo: Frei Francisco. E ele diz: Vá: não é hora decente de andar; não entrarás. E, insistindo de novo, ele responda: Vá; tu és um simples e idiota; agora não vens a nós; nós somos tantos e tais que não precisamos de ti. E eu estou de novo à porta e digo: Pelo amor de Deus, recolhei-me esta noite. E ele responda: Não o farei. Vá à casa dos Crucíferos e peça lá. Eu te digo

${ }^{25}$ VIANO, 1993, p. 147. 
que se eu tiver paciência e não me abalar, que nisto está a verdadeira alegria e a verdadeira virtude e salvação da alma. ${ }^{26}$

Terminamos na convicção de que Pier Paolo Pasolini, sem proselitismo, não busca angariar adeptos para ideologias quaisquer. Seus filmes nos parecem querer mostrar tão somente o que proclama a pregação dos fradinhos: "Amore! Amore!" De forma espantosa, obscena, violenta, alguns; de forma doce e delicada outros. Como em Ucellacci e Uccellini, se o templo se torna invadido, há que expulsar, à força de pauladas, os vendilhões (referimo-nos à cena na qual frei Cicilo já não consegue rezar por causa do assédio de seus devotos e também à reação irada de Totó, o invasor da propriedade "privada" que se insurge contra os proprietários que tentavam escorraçá-lo a tiros e pauladas).

${ }^{26}$ DE VERA ET PERFECTA LAETITIA. In: http://www.procasp.org.br/ fontes.php (...) una die beatus Franciscus apud Sanctam Mariam vocavit fratrem Leonem et dixit: "Frater Leo, scribe". Qui respondit: "Ecce paratus sum". "Scribe - inquit - quae est vera laetitia. Venit nuntius et dicit quod omnes magistri de Parisiis venerunt ad Ordinem, scribe, non vera laetitia. Idem quod omnes praelati ultramontani, archiepiscopi et episcopi; item quod rex Franciae et rex Angliae: scribe, non vera laetitia. Item, quod fratres mei iverunt ad infideles et converterunt omnes ad fidem; item quod tantam gratiam habeo a Deo quod sano infirmos et facio multa miracula; dico tibi quod in his omnibus non vera laetitia. Sed quae est vera laetitia? Redeo de Perusio et de nocte profunda venio huc et est tempus hiemis lutosum et adeo frigidum, quod dondoli aquae frigidae congelatae fiunt ad extremitates tunicae et percutiunt sempre crura, et sanguis emanat ex vulneribus talibus. Et totus in luto et frigore et glacie venio ad ostium, et postquam diu pulsavi et vocavi, venit frater et quaerit: Quis est? Ego respondeo: Frater Franciscus. Et ipse dicit: Vade; non est hora decens eundi; non intrabis. Et iterum insistenti respondeat: Vade; tu es unus simplex et idioata; admodo non venis nobis; nos sumus tot et tales, quod non indigemus te. Et ego iterum sto ad ostium et dico: Amore Dei recolligatis me ista nocte. Et ille respondeat: Non faciam. Vade ad locum Cruciferorum et ibi pete. Dico tibi quod si patientiam habuero et non fuero motus, quod in hoc est vera laetitia et vera virtus et salus animae. 
Em suas misturas interiores, o poeta da imagem apenas se revela um pequeno, um ser de abismos mas também um homem de boa vontade como queriam Cristo, o Francisco, o apóstolo Paulo e tantos comunistas primitivos.

Infelizmente, o que não passava de uma fábula de homens e corvo, tornou-se profecia e o cineasta, poeta e tradutor, como o animalzinho do filme, que aliás se afirma claramente como profeta, foi brutalmente assassinado em Roma, em 1975. Ainda assim, Uccellacci e Uccellini parece seguir a recomendação do pai Francisco na Regra não bulada: "E cuidem de não se mostrar tristes por fora e sombrios hipócritas; mas se mostrem alegres no Senhor (cfr. Fl 4,4) e bem humorados e convenientemente amáveis."

Morto o corvo, voa no céu um avião que anula as estradas e supera o tempo. Fica na memória a belíssima cena de frei Cicillo estalando a língua, gritando e correndo a pregar para os Gavióes, Amore! Amore! Volta diante dos olhos, outra vez frei Cecillo e frei Nineto em coreografia pardalítica dançando, Amore! Amore!

\section{Referências}

FONTES FRANCISCANAS. http://www.procasp.org.br/fontes.php?cfonte=1 AMOROSO, Maria Betânia. Pier Paolo Pasolini. São Paulo: Cosac e Naify, 2002.

MAGGI, Armando. The Resurrection of the Body: Pier Paolo Pasolini from Saint Paul to Sade. Chicago: The University of Chicago Press, 2009.

${ }^{27}$ In: http://www.procasp.org.br/fontes.php. Regra não bulada, Cap. VII: Do modo de servir e trabalhar. Et caveant sibi, quod non se ostendant tristes extrinsecus et nubilosos hypocritas; sed ostendant se gaudentes in Domino (Phil 4,4) et hilares et convenienter gratiosos. 
PASOLINI, Pier Paolo (roteiro e direção). Uccellacci e uccellini. Itália: Alfredo Bini/Arco Film, 1966.

RESTIVO, Angelo. The nation, the body and the autostrada. In: COHAN Steven; RAE HARK, Ina (Org.). The road movie book. New York: Routledge, 1997. p. 233-248.

SANTOS, Maria Lizete dos. Pasolini e os apelos da dramaturgia. In: <http:/ /www.unincor.br/recorte/artigos/edicao1/1artigomarializete.htm>. Recorte: revista de linguagem cultura e discurso, $\mathrm{n}^{\circ} 1,2004$. p. 1-8.

TAN, Terry. Naturally Speaking: Chinese: Recipes and Home Remedies. Singapore: Marshall Cavendish Editions, 2007.

VIANO, Maurizio Sanzio. A certain realism: making use of Pasolini's film theory and practice. Berkeley/Los Angeles: University of California Press, 1993. p. 146-160.

\section{Resumo}

Neste trabalho propomos uma reinterpretação sucinta do filme Uccellacci e Uccellini, do diretor italiano Pier Paolo Pasolini a partir da rejeição de um rótulo exclusivo para a obra. Nossa leitura vê marcas diversas e ambíguas na narrativa - entre elas, uma evidente associação entre religiosidade e marxismo.

\section{Abstract}

Abstract: In this work we propose a very concise reinterpretation of the movie Ucellati e Ucellini, from the director Pier Paolo Pasolini, supported on a rejection of an exclusive label to the work. Our reading sees diverse and ambiguous marks in the narrative - among them, a clear association between religiosity and Marxism.. 